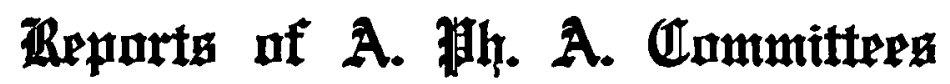

\section{THE PROGRESS OF PHARMACY}

Abstracts from the Report on the Progress of Pharmacy for the year 1911, by C. Lewis Dichl, Reporter.

\section{(Fifth Installment)}

Atropa Belladonna: Infuence of Nutritive Elements on Growth and Alkaloid Content.$S$ Vreven and $C$. Schreiber observe that wild belladonna is generally more active than the cultivated plant, and conjecture that this may usually be attributed to the influence of nutritive elements of the soil upon which it grows. The wild plants grow on ground chosen by themselves as best adapted to their vitality; the cultivated plants grow on soil chosen for them, which may not contain the necessary constituents favorable to the normal formation of alkaloidal bases. The small proportion of alkaloid so of ten found in the cultivated plants may be attributed either to deficiency or excess of the necessary food, or to want of equilibrium among the nutritive elements, nitrogen, phosphoric acid, and potash. Experiments have been made with soil deprived of the nutritive elements, and adding to it suitable manure. The results are summarized thus: Belladonna is shown to be very susceptible to the action of phosphoric acid, nitrogen, and especially potash. The want of these elements is seen in a distincr lowering of the yield. Plants cultivated in pots containing no added manure perish rapidly. The depression in the yield is much more pronounced in the roots than in the other organs of the plant. The time of flowering is retarded by absence of nitrogen and phosphorous, but not by that of potash. Plants deprived of the three elements referred to present a characteristic coloration; without nitrogen, they are chlorotic ; without phosphorous, there is a violet tint, particularly of the veins; without potash, the plants are flabby. As to the alkaloidal content, the leaves of plants, grown on soil poor in nitrogen or phosphorous, contain little alkaloid, while in the case of plants cultivated in the absence of potassium salts, the leaves are rich in alkaloid. The experiments were made with a fertilizer having the following composition: Ammonium nitrate, 10 gms.; sodium phosphate, 12 gms.; potassium carbonate, 5 gms. ; calcium carbonate, 4 gms.; magnesium carbonate, 4 gms. The results obtained by omitting one or other of the ingredients are as indicated above. The cultures were made on a muddy earth of average consistence (l'alluvion de la Herck), to 22 kilograms of which the above quantity of nutritive mixture was added.-Pharm. Jour. and Pharmacist, June 24, 1911, 843; from Ann. de Pharm., March, 1911, 97.

Bryonia Dioica: Constituents of the Root. - The principal constituent of the root Bryonia dioica described by previous investigators is bryonin, a glucoside body to which various formulas have been assigned. Dr. F. B. Power and Dr. C. W. Moore have now subjected this root to a full chemical examination with the following results: The drug contains an enzyme which causes the hydrolysis of amygdalin, salicin, and also the glucoside of bryony. An alcoholic extract of the drug was prepared and distilled in steam, when a small quantity of volatile oil passed over it. The non-volatile resiclue consisted of a dark aqueous liquid and a brown resin. The aqueous liquid yielded to the ether a colorless crystalline neutral substance, $\mathrm{C}_{30} \mathrm{H}_{30} \mathrm{O}_{5}$, melting at $220-222^{\circ}$, specific rotation (a) $\mathrm{D}=$ $+58.6^{\circ}$. By treatment with amyl alcohol a yellow bitter amorphous glucosidic product was obtained. The aqueous liquid also contained an amorphous alkaloidal principle and a sugar giving an osazone melting at $208^{\circ}$. $210^{\circ}$. The brown resin was extracted in the usual way with various solvents, but it was only from the petroleum ether extract that any definite products were obtained. This yiclded a phytosterol, $\mathrm{C}_{27} \mathrm{H}_{48} \mathrm{O}$, which is optically inactive, oleic, linolic, palmitic, and stearic acids, and a dihydric alcohol, bryonol, $\mathrm{C}_{22} \mathrm{H}_{34} \mathrm{O}_{2}(\mathrm{OH})_{2}$. which gives color reactions similar to those of the phytosterols. This alcohol belongs to the series $\mathrm{CnH}_{2} \mathrm{n}_{8} \mathrm{O}_{4}$, of which three other members, ipurganol, 
$\mathrm{C}_{21} \mathrm{H}_{32} \mathrm{O}_{2}(\mathrm{OH})_{2}$, grinderol, $\mathrm{C}_{23} \mathrm{H}_{39} \mathrm{O}_{2}(\mathrm{OH})_{2}$, and cucurbitol, $\mathrm{C}_{34} \mathrm{H}_{36} \mathrm{O}_{2}(\mathrm{OH})_{2}$, have been previously described by Dr. Power. The authors have also examined bryorrin, and conclude that it is a complex mixture not entircly glucosidic in character. Physiological experiments made by Dr. Dale showed that bryonol and the alkaloidal substance are purgatives, but the glucoside is inactive.-Pharm. Journ. and Pharmacist, May 13, 1911, 626.

Digitalis: Action of old Powder on $\mathrm{Hy}$ drogen Dioxide. $-\mathrm{E}$. Choay communicates the results of an investigation regarding the action of old digitalis powder on hydrogen dioxide. A quantity of fresh leaves of Alsace digitalis was divided into three lots and dried: (1) in vacuo in the cold; (2) in the air; (3) in an oven at $40^{\circ}$. The dried leaves, powdered, were placed in desiccators. After five months, the powder from (1) was still quite green, and possessed the odor of the fresh leaves. The powders were then tested to see if they still retained the property of decomposing hydrogen dioxide, and if so, if they had different degrees of catalytic activity. For the purpose of comparison, $1 \mathrm{gm}$. of each powder was macerated for two hours at $15^{\circ}$, in $40 \mathrm{cc}$. of distilled water, when there was added $10 \mathrm{cc}$. of 12 -volume, neutral, hydrogen dioxide; after an hour's contact, the titre was taken in each case on $5 \mathrm{cc}$. of the filtered liquid, with a solution of permanganate (3.14 gms. $\mathrm{KMnO}$, per litre). A parallel series of tests was made of macerations of $1 \mathrm{gm}$. of the powder and $40 \mathrm{cc}$. of water, but before the addition of hydrogen dioxide the liquids were boiled for ten minutes and the original weight made up after cooling, and then titrated with permanganate under the same conditions. $A$ control mixture made with $40 \mathrm{cc}$. of water and $10 \mathrm{cc}$. of the hydrogen dioxide showed that $5 \mathrm{cc}$. required $21 \mathrm{cc}$. of the permanganate solution. The results obtained were as follows: Powder (1), maceration not boiled, required $9.9 \mathrm{cc}$. of permanganate ; boiled maceration, $22.1 \mathrm{cc}$. of permanganate. Powder (2), respectively, 13.3 cc. and 23.2 cc. Powder (3), respectively, $20.5 \mathrm{cc}$. and $22.2 \mathrm{cc}$. The author concludes that the method of drying the leaves has a considerable influence on the catalytic activity. Indeed, after five months' preparation this activity is about twenty times greater for the leaves dried in vacuo in the cold than for those dried in an oven; those dried in the air appear to have an intermediate activity.-
Pharm. Journ, and Pharmacist, May 31, 1911, 621; from Jour. de Pharm. et Chim., 1911, 2,343 .

Rhubarb: Constituents.-F. Tutin and $\mathrm{H}$. $W$. Clewer have contributed a paper detailing the results of their researches on the constituents of rhubarb. Sun-dried rhubarb was exhausted with hot alcohol, and the concentrated extract obtained by evaporation of the alcohol was distilled in steam. The volatile constituents consisted of a small quantity of essential oil and palmitic and hexoic acids. The non-volatile portion was extracted with water, and from the resulting liquid by extraction with ether and treatment of the residue from the ethereal solution with petroleum ether and various alkalies the following substances were isolated: Cinnamic and gallic acids, rhein, a new anthraquinone derivative. $\mathrm{C}_{17} \mathrm{H}_{10} \mathrm{O}_{\text {f }}$ m. p. $297-297^{\circ}$, to which the name rheinolic acid is given, emodin, aloeemodin, emodin mono-methyl ether, and chrysophanic acid. The aqueous liquid yielded to amyl alcohol a crystalline mixture of glucosides of rhein, emodin, aloe-emodin, cmodin mono-methyl ether, and chrysophanic acid, as well as some tannin, gallic acid, and an amorphous non-glucoside resin; the latter, which, on hydrolysis, yielded cinnamic and gallic acids, thein, emodin, aloe-emodin, emodin mono-methyl ether, and chrysophanic acid, and a new compound having the formula, $\mathrm{C}_{14} \mathrm{H}_{12} \mathrm{O}_{8}$, m. p. $256^{\circ}$, probably trihydroxydihydroanthracene. This resin is the principal purgative constituent of the drug. Dextrose in a crystalline state, and levulose were also obtained from the aqueous liquid. The water-insoluble portion of the non-volatile substance yielded to petroleum ether a mixture of palmitic, stearic, oleic, linolic, and linolenic acids, and also a phytosterol (verosterol), $\mathrm{C}_{77} \mathrm{H}_{48} \mathrm{O}$, as well as rhein, rheinolic acids, emodin, aloe-emodin, emodin monomethyl ether, chrysophanic acid, a trace of a substance not melting at $340^{\circ}$, and more of the crystalline mixture of glucosides. The presence of aloe-emodin in rhubarb has not been previously recorded. It therefore appears that the "rheoanthra-glucoside" of Tschirch and Henberger was a mixture of the crystalline glucosides of the anthraquinone derivatives, and the non-glucosidic resin referred to, while "rhabarberone" and "isoemodin" were simply impure aloe-emodin.Pharm. Journ. and Pharmacist, April 22, 1911, 529. 
Ergot: Active Constituents and Assay.A. Kazay contributes an interesting paper on the active constituents of ergot and their assay. According to Tanret, Kobert, and Keller, the chief active constituent of ergot i. the white crystalline substance ergotine, $\mathrm{C}_{86} \mathrm{H}_{40} \mathrm{~N}_{4} \mathrm{O}_{4}$. For the detection of this substance the Hungarian Pharmacopcia adopts Keller's test, which is as follows: The substance is dissolved in concentrated acetic acid containing a little ferric chloride, and concentrated sulphuric acid poured on. A violet-blue layer is formed at the surface of separation of the two liquids. Ergotinine is an unstable substance, and in presence of moderately concentrated acids changes into cornutine, an amorphous water-soluble body, which gives a red iridescent layer by Keller's test. The author was unable to get anything but the red color of cornutine by Keller's test when using commercial preparations of ergot which had been exposed for some time to a high temperature in the process of manufacture. In order to investigate the relationship of cornutine to ergotine the author prepared an extract by Keller's process. The color layers obtained by the above test were examined spectroscopically. With cornutine an absorption band in the blue portion of the spectrum is obtained, and this was readily observed when testing commercial extracts. The parahydroxyphenylethylamine of Berger and Dale is probably a decomposition product of ergotine or of proteid matter. Several other active constituents of ergot have been described, but none gives any characteristic reaction which might be used to detect the presence of ergot. For this purpose the presence of the coloring matter sclerythrin must be proved by a spectroscopic examinatian. For the assay of ergot preparations the author recommends extraction with ether after treatment with alkali and determination of the nitrogen in the residue from the ethereal extract, by a modification of Kjeldahl's method.-Pharm. Journ. and Pharm., April 15, 1911, 499, from Ztschr. d. Allgem. Aestr. Apoth. Ver. (1910), 547.

Helianthus Annurs: Basic Constituents of the Flowers.-In Russia various parts of the sunflower are in common use for medicinal and other purposes, tinctures prepared from the fresh flowers and leaves being used in domestic practice as a substitute for quinine. In the belief that the activity of the flower depended on alkaloidal substances, E. Busch- mann examined an extract prepared from the flowers and stalks of the plant. When this was dissolved in water, fatty and resinous substances separated, which were removed by shaking out with petroleum ether; the aqueous liquid was then precipitated by bismuth potassium iodide, the precipitate washed and decomposed by lead oxycarbonate, and the alkaloidal solution acidified with hydrochloric acid and concentrated. Crystals of betaine hydrochloride were thus obtained, and after as much as possible has been removed, the mother-liquor was examined and found to contain choline chloride. The two bases betaine and choline were identified by preparing and analyzing a considerable number of characteristic double salts and other compounds. No other basic substance was found, but it appeared that the proportion of these two bases present was enough to account for the observed activity of the extract.-Arch. d. Pharm. 240 (1911), No. $1,1$.

Mangrove Bark: Uses and Constituents.$H$. Bocquillon says that there are two classes of mangrove bark, the red and the grey, which are used industrially as a tanning substance and therapeutically as a remedy for leprosy, both varieties represented in a number of species, forming trees 4 to 6 meters in height. The red belong to the Rhizophoracex, the grey to the Combretacex. The species (red) employed in therapeutics are $R$. mangle, $R$. mucronata, Bruquiera gymnorhiza, and Coccoloba uvifera; the species (grey) used therapeutically are Conocarpus erecta, and Avicennia tomentosa. Analyses of the barks of the various species give similar results; the ash is 5.5 per cent., consisting of carbonates and chlorides of potassium, sodium, calcium, and iron. The percentage composition of the bark is given as follows: Wax, 0.335 ; fatty matter, 0.335 ; tannin, 20.00 ; resin, 13.55; starchy matter, 5.00; glucoside, very abundant; alkaloid, none. The red coloring matter becomes cherry-colored with alkalies turning to yellow, with formation of a precipitate with acids. Mangrove is used in the same forms as cinchona-powder, tinctture, soft extract, syrup, wine, and especially liquid extract, and decoction. The dose of the liquid extract is $5 \mathrm{gm}$. twice daily, increasing to $30 \mathrm{gms}$. twice daily if desired; the dose of the soft extract is from 2 to 8 . gms. daily. Used in leprosy, it is administered in the form of liquid extract, in doses of $10 \mathrm{gms}$. daily, but in two instalments, in- 
creasing by $5 \mathrm{gms}$. a day up to $60 \mathrm{gms}$. The soft extract is given in $8 \mathrm{gm}$. doses daily, but in this form gastric intolerance and giddiness are sometimes produced. The drug is also used in the form of baths and lotions, and the decoction contains 30 gms. per litre. Amelioration of the disease is observable in fifteen days, but the cure requires a year. Besides its use in leprosy, mangrove is valued in the colonies as an astringent in lotions for the eye-trouble; internally it is used in diarrhcea and for tuberculosis, while the powdered bark is used as a febrifuge.-Pharm. Journ. and Pharmacist, June 24, 1911, 843; from Rep. de Pharm., May, 1911, 195.

Ash Secds: Properties of the Fixed Oil.An investigation of the fixed oil, extracted by W. Bach from the seeds of the ash (Fraxinus) in a yield of $9.7 \%$, shows this oil to have the following characters and constants: It was brownish yellow, moderately viscous, and had an odor resembling that of tea. It possessed the following constants: Specific gravity, 0.9181 ; saponification value, 168.5; iodine value, 129.5; Reichert-Meissl value, 1.68. The unsaponifiable portion amounted to 5.5 per cent. and consisted of phytosterol. The freshly-prepared oil contained 1.71 per cent. of free acid, reckoned as oleic. The fatty acids obtained by saponification of the oil melted at $36.8^{\circ}$ and solidified at $28.6^{\circ}$, and had an iodine value of 125.8 and saponification value of 181.7. The oil appeared to resemble the oils of soya beans and of sunflower seeds, and to possess very feeble drying properties, an exposed thin film not being hard after fourteen days.-Pharm. Journ. and Pharmacist, June 24, 1911, 843; from Chem. Ztg., May 4, 1911, 478.

Cork: Chemical Nature and Constituents. -It is well known that cork contains a substance, suberin, which can be saponified with potassium hydroxide solution. From this solution, in addition to other fatty acids, phellonic acid can be isolated. This acid is, according to the author, a hydrocyclic substance. On oxidation the ring is broken and the aliphatic phellogenic acid or its isomer isophellogenic acid is obtained. In contradicton to other workers, M. von Schmidt now has shown that the portion of cork soluble in chloroform contains not only cerin but also glycerides of fatty acids, and that the true cork substance is free from these substances. Investigations of the chemical nature of cork have shown that phellonic acid forms anhydrides, and these anhydrides are present in cork, along with polymers of liquid and solid fatty acids. On heating the crude fatty acids from cork, water is split off, and a product is obtained which is completely insoluble in indifferent solvents. The fatty acids thus changed are unalterable by further heat, they are impermeable to gases, and represent the true cork-substance. If filter paper, or better, fine sawdust, is saturated with the fatty acids, and then heated to $140^{\circ}$ a substance is obtained which is indistinguishable from cork, except that the structure is absent. Besides phellonic acid, there appears to be three other fatty acids present in cork.-Pharm. Journ. and Pharmacist, April 1, 1911, 433; from Oest Chem. Ztg., 1911, 21.

Burnt Sponge: Constituents.-The charcoal obtained by the ignition of sponge without free access of air has had more or less application in medicine since before the discovery of iodine in 1811 by Courtois, and a tincture of such charcoal (Spongia Usta) enters into homœopathic pharmacy. Recorded investigations into the constituents of burnt sponge have shown very different results, and it appears that the material found in commerce does vary considerably. Seven samples, obtained from different sources, contained from 0.31 to 0.81 per cent. of iodine, 7.92 to 23.16 per cent. of lime $(\mathrm{CaO})$ as calcium carbonate, 1.05 to 2.21 per cent. of iron, and from 3.35 to 15.30 per cent. of sand. Tinctures prepared with 90 per cent. and 60 per cent. alcohol, and analyzed, showed that the latter was more suitable for dissolving the principal constituents. The average amount of iodine in a number of samples of the tincture was 0.075 per cent.-Apoth. $Z_{\mathrm{tg}}$. XXVI (1911), No. 33, 317.

Tincture of Strophanthus: Proposed Process of Preparation and Assay.-J. Haycock discusses the different methods of assaying strophanthus seeds and the tincture, and recommends the following which, as applied to the seeds, may also be used for standardizing the tincture.

(1) Twenty $\mathrm{gm}$. of the powdered seeds are percolated with either petroleum ether or ethyl ether, to remove the oil, as it has been proved beyond doubt that neither of these solvents dissolve any appreciable amount of strophanthin.

(2) The seeds so treated, are then perco- 
lated with $70 \%$ alcohol until exhausted; the tincture is craporated to a soft extract at a low temperature, the extract dissolved in 100 cc. of water and the solution filtered into a separator.

(3) Then add to the filtrate 2 cc. of $25 \%$ $\mathrm{I}_{2} \mathrm{SO}$, and shake out the resulting mixture three times with $20 \mathrm{cc}$. of ether, to get rid of any trace of oil that might be present.

(4) The aqueous solution of the extract, after this treatment, is warmed on a water batl for onc hour at $75^{\circ} \mathrm{C}$., whereby the strophanthin is split into strophanthidin and strophanthobiose methyl ether.

(5) When cool, the liquid is returned to the separator and shaken out three times successively with $10 \mathrm{cc}$. of chloroform, which dissolves the strophanthidin, and leaves it on evaporation to a small bulk in a tared dish, crystallization being facilitated by the addition of a little alcohol; it is finally dried below $65^{\circ} \mathrm{C}$. and weighed.

The author suggests that the Tincture of Stropantlus be made in accordance with the above observations-removing the oil from the seeds, percolating the oil-freed seeds with $70 \%$ alcohol, and adjusting the percolate to a standard of $0.1 \% \mathrm{w} / \mathrm{v}$ strophanthin by the process described. This chemical method of standardization is regarded by the author to be quite as good, if not better, than the present method of physiological assay.-Pharm. Journ. and Pharmacist, April 29, 1911, 553.

Birin: Chemical Constitution.-A. Heiduschka and HI. Riffart observe that, although bixin has long been known as a constituent of Bira orcllana, its constitution has not been established. The formula assigned by $Z$ wick, $\mathrm{C}_{3} \mathrm{H}_{20} \mathrm{O}_{2}(\mathrm{OH})_{2} \mathrm{OCH}_{2}$, appears to be erronous; only one hydroxyl group is present, and the di-potassium salt is only formed by the saponification of the methoxyl group. The empirical formulæ, $\mathrm{C}_{20} \mathrm{H}_{84} \mathrm{O}_{5}$ and $\mathrm{C}_{28} \mathrm{H}_{34} \mathrm{O}_{6}$, have both been given for bixin, and the latter appears to be the correct one. If bixin is brominated in glacial acetic solution, ten atoms of bromine are added, and the product contains 62.48 per cent. of bromine; but if the bromination is carried out in chloroform solution, the product contains $\mathbf{7 1 . 4 5}$ per cent. of bromine and appears to be a tetrahydromide of the decabrombixin, $\mathrm{C}_{23} \mathrm{H}_{88} \mathrm{O}_{3} \mathrm{Br}_{14}$, or $\mathrm{C}_{23} \mathrm{H}_{24} \mathrm{O}_{3} \mathrm{Br}_{10}, 4 \mathrm{HBr}$. Similarly, chlorination of bixin in chloroform solution gives a compound containing 51.92 per cent. of chlorine, corresponding to the formula $\mathrm{C}_{28} \mathrm{H}_{34} \mathrm{O}_{5} \mathrm{Cl}_{10}$, $4 \mathrm{HCl}$. The iodine absorption value of bixin, determined with either Wijs' or Hubl's solution, agreed with the addition of ten atoms of iodine. Dry hydrochloric acid gas acting on bixin in chloroform solution gave the compound $\mathrm{C}_{28} \mathrm{H}_{34} \mathrm{O}_{5} \mathrm{HCl}$.-Arch. d. Pharm. 249 (1911), No. 1, 39.

Starch: Preparation as an Indicator.-L. Mathiew observes that in using starch as an indicator in end reactions with iodine solutions there is often indistinctness of the terminal point, when the bluc color may be evanescent or the color may vary from violet to rose, due to the presence of dextrin. Further, starch solutions may contain swollen grains, which retain the blue color somewhat persistently, and thus destroy the delicacy of the end reaction. The author, therefore, advises the use of soluble starch, which he prepared thus: The starch flour is digested for some time with a solution of hydrochloric acid, 1 in 1,000, then washed with distilled water, dried at $30^{\circ}$, and heated for some hours in an oven at about $100^{\circ}$. The weak acid treatment takes out traces of alkaline bases and alkaline earths, and transforms neutral phosphates into acid phosphates. When it is reduced to the dry heat its physical state is gradually modified into that of a soluble starch. The starch thus prepared and dried keeps perfectly. For use as a reagent $1 \mathrm{gm}$. is dissolved by boiling for a few moments with $100 \mathrm{cc}$. of water and filtering. The resulting solution is very limpid, free from granules, and with iodine is colored purc blue, the blue color being instantly discharged on removal of the excess of iodine. The use of preservatives is condemned.-Pharm. Journ. and Pharmacist, April 1, 1911, 433; from Ann. de Chim. Analyt. 15 (1911), 51.

Phenol: Simplc Method of Determination of the G. P. V.-F. Lehmann directs attention to the method of the G. P. V. for determining phenol, which satisfactorily corrects certain errors in the "tribromide" method formerly official. The process consists in adding to a solution containing phenol known quantities of solutions of potassium bromide and bromate, acidifying with sulphuric acid, and shaking in a stoppered flask; after fifteen minutes standing the excess of bromine is determined by adding potassium iodide 
and titrating with thiosulphate. If the bromate solution is made to contain $1.6702 \mathrm{gms}$. of $\mathrm{KBrO}_{8}$ in 1 litre, $50 \mathrm{cc}$. of it corresponds to $30 \mathrm{cc}$. of $\mathrm{N} / 10$ thiosulphate; if therefore $50 \mathrm{cc}$. of the bromate solution is employed in a given case, the number of cc. of thiosulphate used is to be deducted from 30 , and the difference multiplied by 0.001567 gives the weight of phenol precipitated.-Apoth. Ztg. XXVI (1911).

B-Amino-ethyl-glyoxaline: One of the Active Principles of Ergot, obtained by Synthesis.-Dr. F. L. Pyman has applied Gabriel's method for the preparation of glyoxaline derivatives to the production of 4 - (or 5 ) B-amino-ethylglyoxaline, one of the active principles of ergot, on a commercial scale. Diaminoacetone is treated with potassium thiocyanate, and the resulting compound on removal of the sulphur yields 4-aminomethylglyoxaline. This is converted successively into the alcohol by means of nitrous acid, into the chloride by means of sodium hypochlorite, and into the cyanide by means of potassium cyanide. The cyanide then on reduction yields the 4-B-amino-ethyl-glyoxaline, which, as obtained by this method of synthesis, is a very reactive substance.-Pharm. Journ. and Pharmacist, April 22, 911, 530.

Ozone: Generation by a Chemical Method. -P. Malaquin has made an addition to the small number of purely chemical processes by means of which ozone may be generated. When ammonium persulphate, 20, is heated on the water-bath with nitric acid, specifir gravity 1.310 , reaction takes place rapidly at 65 to $75^{\circ} \mathrm{C}$. with evolution of gas. This gas is found to consist of 3 to 4 per cent. of ozone, 4 to 4.5 per cent. of nitrogen, less than 1 per cent. of carbon dioxide, and the rest oxygen. Gas is evolved very slowly at the normal temperature of the laboratory; and more rapidly at 50 to $60^{\circ} \mathrm{C}$., but with considerable rapidity at the temperature above indicated. The author has devised, and figures, a special apparatus, wholly of glass, for the generation of ozone by this process. Although the yield of ozone is not very high, the method affords a convenient means for its production. The persulphates of potassium and of sodium do not appear to yield so much ozone with nitric acid as the ammonium salt.-Pharm. Jour. and Pharmacist, May 6, 1911, 587 ; from Journ. de Pharm. et Chim., 1911, 3,329.

\section{REPORT OF COMMITTE ON DRUG MARKET.}

(Continued from page 375 )

Copaiba. Ten samples were free from fixed oils, turpentine and paraffin oils, but eight of them contained gurjun balsam. $R$. P. McKeogh. The test for gurjun in copaiba is too delicate for use in inexperienced hands, often giving very fallacious results. A test for rotary property should be. in the U. S. P. to exclude African Balsam. The oil should be distilled and tested and not be below $-5^{\circ}$. Genuine oil rotates as high as $-35^{\circ}$. Druc Topics.

Coro. This drug continues unobtainable, according to the statement of importers. None has been received in the port of New York for several years, H. H. RusBy. Para-coto. This drug has been almost unobtainable and almost everything that has been offered under this name has been spurious, eight different barks having appeared under this name during the year. $H$. H. RUSBY.

Cream Tartar. Two samoles offered as strictly U. S. P. tested $\mathbf{9 6 . 4 8}$ per cent and 98.72 per cent only. E. H. Gave.

Cresol. One lot rejected, as it contained a large percentage of phenol. E. H. GANE.

CunEB. The official standards for this article should be carefully revised, after a thorough investigation of the relative values of the different forms of the drug. The definition calls for the "unripe but fully grown fruit," but there are the best of reasons for believing that the fruits when not more than half grown are far richer in active constituents than when fully grown. Certainly the percentage of oil is then very much greater. Before the official definition can be revised intelligently, the relative percentage of all the other constituents should be carefully investigated, and if the present indications should be thus verified, the words "but fully grown" should be deleted. H. H. RUSBY.

Cunbear. Varies much in quality.

$\begin{array}{cccc}\text { Sample } & \text { Moisture } & \text { Ash } & \begin{array}{c}\text { Chlorine in } \\ \text { Ash as } \mathrm{NaCl}\end{array} \\ \mathbf{1} & 7.0 & 11.7 & 1.88 \\ 2 & 4.8 & 42.7 & 31.23 \\ 3 & 10.5 & 66.8 & 59.80 \\ 4 & 4.95 & 48.85 & 42.40 \\ 5 & 3.0 & 66.25 & 60.70 \\ 6 & 6.7 & 4.40 & \text { Trace } \\ & \text { Dye } & \text { Filtrate } & \text { Dying on } \\ \text { Sample } & \text { test } & \text { from. } & \text { Cotton, Alum } \\ & \text { Arata } & \text { Lead S. S. } & \text { Mordant } \\ 1 & \text { O.K. } & \text { Slt. pink } & \text { Slt. color } \\ 2 & \text { O.K. } & \text { Slt. pink } & \text { Colorless } \\ 3 & \text { O. K. } & \text { Slt. pink } & \text { Slt. color } \\ 4 & \text { O. K. } & \text { D'c'd pink } & \text { Slt. color } \\ 5 & \text { O.K. } & \text { D'c'd pink } & \text { Slt. color } \\ 6 & \text { O. K. } & \text { Colorless } & \text { Colorless }\end{array}$

*Presented at the Fifty-ninth Annual Convention. 
Digestive Solution. Claimed to be very active, capable of digesting starches, albumins, fibrins, etc. It tested as follows :

Alcohol, 15.14 per cent; extractive, sug., etc., 27 per cent; 1 part digests albumen, none; converts starch, $21 / 2$ parts; dry fibrin, 0.73 . E. L. Patch.

Digitalis. Increasing doubt is being cast upon the claim that a second year leaf is in any way superior to that of the first year. It is not the province of a pharmacognosist to pass upon such a question, and it is greatly to be regretted that pharmacologists do not determine the case so that we may know how to act in regard to it. There is, moreover, grave doubt as to whether the pharmacologists are on the right track in their tests. Their idea seems to be that the therapeutical value of this drug varies directly with its toxic power upon the animals experimented upon. Now the object of administering Digitalis therapeuticaly is not to kill the patient, and there is no little reason to believe that the therapeutical constituent is not the one that kills the cat. Furthermore, the variation in its percentage may not correspond at all with that in the percentage of the latter. $H$. $H$ RusBy. It has been well determined that leaves of first year growth are equal to or better than those of second year growth, and that a well-cured drug does not deteriorate. See Caesar and LoRetz in Chemist and Druggist. Assays of Digitalis powder over eighteen months showed no appreciable change. E. L. PATCH.

ECHINACEA. Three lots were found to consist of the roots of some species of brauneria other than brauneria pallida, which is the source of true Echinacea. Another lot consisted of the roots of rudbackia fulgida. O. P. \& D. Reporter.

Elixir Calisaya N. F. Twenty-five samples from retail stores: Alkaloids, 0.042 to 0.318 per $100 \mathrm{Cc}$. Color from colorless to nearly black. In several a heavy ppt. RoY A. PECKHAM.

ERGOT. There has been considerable trouble during the year from the offerings of Ergot of poor quality. The importance of a drug of first quality is more important in the case of Ergot than of most drugs, and its quality is exceedingly sensitive to changes which result in only slight differences in appearances and physical properties. Considering that there is no chemical standard for this drug, it thus frequently happens that an importation which demands rejection on therapeutical grounds will appear satisfactory to the ordinary observer; so that a controversy will arise. H. H. RUSBY.

ETHER U. S. P. 1890. Ether that has stood for some time may contain hydrogen dioxide, supposed to be developed by action of ozone, formed by evaporation of Ether, upon the water present. DRUG ToPICs.

Formaldehyde. Often runs a little low owing pehaps to partial polymerisation. Several lots tested 37.2 per cent to 38 per cent. W. L. SCOVILle.

Frangula. A spurious bark, apparently a species of Rhamnus, has been found mixed in considerable quantity with Frangula, and should be carefully watched for by dealers. The bark, in quills of the same size, is much thicker than that of Frangula. It is roughe: on the surface, of a more dull gray, has a shorter fracture, but the resemblance to frangula in some of its forms is rather close. H. H. RusBy. ing :

GambIR. Eight samples gave the follow-

$\begin{array}{lc}\text { Ash } & \text { Soluble in alcohol } \\ 4.03 & 80.8 \\ 4.07 & 78.6 \\ 4.80 & 76.9 \\ 19.3 & 77.5 \\ 22.6 & 78.4 \\ 22.7 & 78 . \\ 31.5 & 79.5 \\ 32 . & 79.5 \\ & \text { J. B. YounG. }\end{array}$

GINGER Root. Jamaica Ginger gave following percentages of alcoholic extract: 6 per cent, 4.6 per cent, 3.3 per cent, 3.5 per cent, 3.3 per cent, 3.8 per cent, 5.9 per cent, 4.6 per cent. E. L. PATCh.

GLYCERIN. Manufacturers pay more attention to getting a colorless glycerin than to purity. In consequence most of the glycerins will develop a bad odor in acid mixture from the fatty acids and aldehydes contained in them. W. L. Scovirie. 5 Cc. glycerin with $5 \mathrm{Cc}$. of water and $1 \mathrm{Cc}$. diluted sulphuric acid, shaken and set aside for fifteen minutes, should not develop a disagreeable odor. A. B. LYONS.

Goldenseal. The small amounts obtainable test high in alkaloid. Seven packages assayed $2.86,3.01,3.26,3.3,2.9,3.5,2.72$ per cent respectively. E. H. GANE. 3.02 per cent, 3.2 per cent, 3.2 per cent. E. L. Patch.

Gum. Advertised as a superior product for tablet making and other pharmaceutical uses. Proved to be white potato dextrine. E. L. PAtch.

HeroIN. Variations in melting point of 10 to 15 degrees are found in Heroin and Heroin Hydrochloride. W. L. Scoville.

Hydrogen Peroxide. Thirty-two samples ranged in strength from 0.63 per cent to 3.49 per cent. Twenty-nine more were below 3 per cent, three less than 2 per cent, and two others less than 1 per cent. Solids ran as high as 0.366 per cent. Eighteen exceeded the limit for acidity. Twenty-four contained Acetanilide. N. A. R. D. Notes.

Hyoscyamis. One sample of annual leaf assayed 0.023 per cent alkaloids. E. H. GANE. 0.057 per cent, 0.097 per cent, 0.118 per cent. E. L. Patch.

INSECT PowDER. Stems are largely used for powdering and the claim is made that these are as active as the flowers. E. H. GANE. Considerable quantities of Insect Flower stems continue to arrive. It seems impossible that they could be used for any other purpose than that of substituting or adulterating insect flower powder. Our histological pharmacognosists have published such descriptions and illustrations of powders adulterated 
in this way, that no one who has had even an elementasy training in the use of the microscope should be at a loss to detect the fraud. H. H. RusBY.

Ipecac. 2.4 per cent, 1.97 per cent, 2.26 per cent, 1.97 per cent, 2.4 per cent, 2.28 per cent, 2.33 per cent, 2.18 per cent, 2.43 per cent. E. L. PATCh.

Iron Lactate. One sample was only partially soluble and contained much ferric lactate. E. H. GANE.

JABORANDI. 0.26 per cent, 0.165 per cent, $0.3,0.2$ per cent. E. L. Patch.

JALAP. The poorest lot offered tested 6.75 per cent and the best 20.06 per cent resin. E. H. GANe.

Total resin $8.05 \%$ Ether soluble $1.2 \%$

Total resin $11.85 \%$ Ether soluble $1.1 \%$

Total resin $12.2 \%$ Ether soluble $1.35 \%$

Total resin $9.78 \%$ Ether soluble $1.18 \%$

Total resin $7.4 \%$ Ether soluble $0.95 \%$

Total resin $13.84 \%$ Ether soluble $1.24 \%$

E. L. Patch.

Kamala. Twelve samples-all free from starch-Ash 7.7, 6.4, 4.5, 6.5, 7.2, 15.7, 7.7, 18.2, 5.3, 24.6, 7.7, 5.2. C. B. W HERLER.

Lemon Extract. Two lots were free from oil. Others 6 per cent upward. M. S. B.

LoBelia Herb. 0.6 per cent alkaloid. E. L. PATCH,

Magnesia Calc. Magnesia labelled "For technical purposes only," but sent for medicinal use, assayed 92.2, 89.7, 86.6, 95.9 and 93.1 per cent respectively. E. H. GANE.

Magnesium Sulphate. Dried tested 95 per cent monohydrated. E. L. PArch. The dried salt, if monohydrated, should contain 87 per cent of anhydrous salt, if dihydrated, 77 per cent: M. C. W. had 67.2 per cent anhydrous, 7.29 per cent water. P. W. R. 64.93 per cent anhydrous, 19.43 per cent water. Merck 54.27 per cent, 26.16 per cent water. W. A. PuCKNer AND $L$. A. W ARreN.

Methylene Blue. Contains 0.1 per cent to 1.0 per cent ash. Zinc is usually present. W. L. SCOVilie.

MUSTARD. The presence of Charlock in Mustard used as a condiment is very common and frequently very excessive in amount. Provisions for its detection in both whole and powdered form should carefully be made in the pharmacopoia. H. H. RusBy.

MYRRH. Is 30.1 per cent to 42 per cent soluble in alcohol. W. L. Scoville.

Nux Vomica. One lot of powdered assayed only 1.19 per cent Strychnine. E. H. GANE. 1.26 per cent, 1.22 per cent, 1.268 per cent, 1.23 per cent, 1.22 per cent. E. L. РАtсH.

Oil Anise. One lot of Manilla oil proved of excellent quality, giving the following results: Congealing point $15^{\circ} \mathrm{C}$. Sp. gr. 0.975 . Opt. rotation $0.25^{1}$. Soluble in all proportions in 90 per cent alcohol. E. H. GANE.

Oil CaJuptr. Lots meeting other U. S. P. requirements are low in gravity, running 0.911 or under instead of 0.915 to 0.925 . $E$. L. Patch.

Oil Cassia. Lots sold as redistilled gave
11 per cent residue and lots marked lead free, not redistilled, only 11.5 per cent residue. E. L. Patch. Cassia Oil and Cinnamon Oil are not alike. The names should not be used interchangeably. Oil Cinnamon is distilled from scrap bark, and if pure, may contain 80 per cent to 90 per cent aldehyde. It is often adulterated with leaf oil. Oil of Cassia is distilled almost entirely from the leaves and contains from 75 per cent upward of aldehyde. Shipped in lead containers it often contains lead. AM. DrugGIST.

Oil Citronella. Frequently adulterated with turpentine and petroleum oil. AM. DRUGGIST.

OIL EuCAlyptus. One sample offered contained only 40 per cent of Eucalyptol. E. H. Gane.

OIl Fennel. Congealing point, $+6^{\circ} \mathrm{C}$. $+3.5^{\circ} \mathrm{C}$., $+5^{\circ} \mathrm{C}$., $+5.50^{\circ} \mathrm{C} .,+6^{\circ} \mathrm{C}$., $+6.5^{\circ} \mathrm{C}$, $-16^{\circ} \mathrm{C} .,+3^{\circ} \mathrm{C}$, $+2.85^{\circ} \mathrm{C}$. E. L. Patch.

The requirements of $+5^{\circ} \mathrm{C}$ is generally agreed to be too severe. Manufacturers abroad tell us the freshly made oil will show as required but almost immediately begins to undergo a natural change, one indication of which is the dropping of the congealing point. This does not impair the quality of the oil. Our last importation was $5^{\circ}$ when it left the factory, was $4.5^{\circ}$ when it reached us, and has gone down further since. Our stock at different times has tested $2.5^{\circ}$ upwards. The way the "pluggers" standardize this is by adding Oil of Anise having a congealing point of $15^{\circ} \mathrm{C}$, an admixture defying detection by any ordinary means. DODGE AND Olcort.

OIL LiNSEED. Is commonly extended with corn oil. Soya bean oil has been used, but to much less extent. E. H. GaNe.

Olive OrL. Various samples were mixtures of Olive Oil and Cottonseed Oil or all Cottonseed. M. S. B.

OIL Origanum. It is stated in N. A. R. D. Notes that no Oil of Origanum genuine is obtainable and Oil Red Thyme is offered instead. There are dealers who guarantee to furnish genuine Oil of Origanum distilled from Origanum vulgare. One such product had sp. gr. 0.910, was soluble in one-half volume of alcohol and one volume of 80 per cent alcohol, and gave 30 per cent phenols and would meet requirements for Oil Red Thyme. E. L. Patch.

ORGANUM. The experiences this year with the different species of Origanum have been most interesting. It has been a revelation to me to find that there are quite a number of species of this genus which possess a strong odor and taste of thymol and which undoubtedly contain a considerable quantity of that substance. This renders them wholly unlike Origanum Majoranum and Origanum vulgare. The medicinal relations of these substitutes are almost nil, but they are considerably imported for use by our Italian citizens as a condiment, and are very frequently imported under the name of thyme. H. H. Rusby. 
Oil Peppermixt. Marked "Twice Rectified," "U. S. P.," "Redistilled." Not always colorless. One lot gave more than opalescence with four parts of 70 per cent Alcohol. Optical rotation $-25.7^{\circ}$ to $-27.4^{\circ}$, Sp. gr. 0.9018 to 0.9045 , Menthyl Acetate 7.08 to 7.86 per cent. Total menthol 55 to 60.3 per cent. E. L. Patch.

OIl Pine Needles. The market shows now few products which were described in the publications of ten years ago, and the name Pinus sylvestris is more misused than any other. There is practically no Oil of Pinus sylvestris on the market. The name is generally applied to such oils as the Siberian and Austrian oils. The Austrian oil is also sometimes known as Oil of Pinus pumilio. Am. Drvgaist.

Oil Red Thyme Flowers. Guaranteed to be genuine. Sp. gr. 0.888 (U. S. P. 0.9 to 0.930 ). Optical rotation $-1.2^{\circ}$ (U. S. P. up to $3^{\circ}$ ). Phenols 22.5 per cent. E. L. Patch. Oil Sassafras-

$\begin{array}{ccc}\text { Sp. gr. } & \text { Opt. Rotation } & \text { Refractometer } \\ 1.0672 & +2.8^{\circ} & \\ 1.075 & +2.70^{\circ} & 1.5315\left(20^{\circ} \mathrm{C}\right) \\ 1.071 & +2.30^{\circ} & 1.5302\left(23^{\circ} \mathrm{C}\right) \\ 1.0654 & +2.5^{\circ} & 1.5262\left(22^{\circ} \mathrm{C} .\right) \\ 1.0574 & +3.3^{\circ} & 1.5234\left(23^{\circ} \mathrm{C} .\right)\end{array}$

Last shipment returned, dealer's explanation:

"An inexperienced man overlooked the fact that Oil Sassafras solidifies in cold weather and drew from the top of a container, the contents of which were not thoroughly melted and mixed." E. L. PATCH.

Paw Paw. Paw paw preparations vary greatly in digestive activity. W. L. Scoville.

PaPAIN-

Dry Beef Fibrin digested:

Neut. Sol. 21.8 Alk. Sol. 25.5

Neut. Sol. 8.6 Alk. Sol. 19.45

Neut. Sol. 21.6 Alk. Sol. 23.9

Neut. Sol. 13.5 Alk. Sol. 16.9

Neut. Sol. 12. Alk. Sol. 17.6

Neut. Sol. 12. Alk. Sol. 14.5

Neut. Sol. 10.3 Alk. Sol. 14.8

Neut. Sol. 19.5 Alk. Sol. 24.2

"Juice of Pawpaw":

Neut. Sol. 16.5 Alk. Sol. 20.

E. L. Patch.

PePsin. Samples on the market with digestive power of 1-9000, but they contain a large proportion of inorganic salts. Probably these salts are a large factor in the activity of the pepsin. W. L. Scoville. Three lots labeled 1-6000 were 1-2000. One lot labeled 1-3000 was 1-1000. Several other lots were weaker than labeled. O. P. D. REPORTER.

Peroxide Creams. Of twenty-one brands only three contained hydrogen dioxide and in a majority of cases apparently no dioxide had ever been present. Am. Drugarst. The Peroxide Specialty Co., Cincinnati, were convicted and fined for shipping such a product. Pharm. ERA.

Petrolatum White. Sold under guarantee as U. S. P. All free from fats.

Color white, odorless, fusing point $30^{\circ} \mathrm{C}$., character, fairly transparent; white, odorless, $34^{\circ}$ to $35^{\circ} \mathrm{C}$., fairly transparent; white, odorless, $38^{\circ}$, more translucent: white, odorless, $35^{\circ}$, fairly transparent; white, odorless, $42^{\circ}$, more translucent; bluish white, odorless, $36^{\circ}$, translucent; white, odorless, $38^{\circ}$, opaque. E. L. PATCh.

Petrolatem Liquidim. It is difficult to obtain meeting the U. S. P. requirements for sp. gr. of 0.870 to 0.940 . A few lots run as follows: $0.860,0.875,0.876,0.877,0.861,0.877$. E. L. Patch.

Phenacetin. Melts at $131^{\circ}$ to $135^{\circ} \mathrm{C}$. W. L. SCOVILIE.

Pills Cathartic Compound. These and other black pills labeled gelatin coated were coated with lamp-black and glucose. Pills Cathartic Compound are being offered at wholesale below the bare cost of material. N. A. R. D. Notes.

Pinkroot. Fifty-seven samples were obtained from various sections of the country and carefully examined, compared with four plants of true spigelia from the Bureau of Plant industry, cross sections of the rhizomes and roots being made and compared microscopically. Specimens found to be true pinkroot, none, although many were up to the U. S. P. description. C. E. SANDers.

Popopyyuty. Alcohol insol.

$\begin{array}{rr}1.5 & 0.5 \\ 1.2 & 0.5 \\ 1 . & 0.5 \\ 1 . & 0.4 \\ 3.7 & -0.5 \\ 0.8 & 0.5 \\ 1.2 & -1.0 \\ 11.8 & 1.0 \\ 3.1 & \end{array}$

E. L. PATCH

Potassium Carbonate. Usually contains 8 to $15 \%$ of water. Since the pharmacopoia directs that it is to be dried before being weighed for titration, salt containing as much as $15 \%$ of water is sold as U. S. P. W. L. Scoville. 1 lot $0.7 \%$ Chloride-98\% $\mathrm{K}_{2} \mathrm{Co}_{2}$ in well dried salt. Dirty. Makes dirty solution. No. 2 do. No. $3,98.5 \%$ dirty. E. L. PATCH.

Potassa-Highest Purity. Potassium Hydroxide runs $85 \%$ to 89 or $90 \%$ strength. W. L. SCOVILIE.

Potassilim Nitrate U. S. P. Conviction and fine for shipping ten bbls. containing $7 \%$ Sodium Chloride. U. S. P. should be $99 \%$ pure. APOTHECARY.

Precipitated Ferrocs Phosphate. Dispensatory states that it may assay $44 \%$ ferrous phosphate. Five lots carefully made assayed $63.5 \%, 65.95 \%, 69.74 \%, 71 \%, 80.34 \%$, $86.8 \%$. Other lots in market, $42.34 \%, 45 \%$, $49.98 \%, 44 \% \mathrm{Fe}_{3}\left(\mathrm{PO}_{1}\right)_{2}, 8 \mathrm{H}_{2} \mathrm{O}$. E. L. PATCH.

Rhunarb. American rhubarb has been offered to the trade. The root is of a poor, grayish color, very spongy and with little if any of the characteristic rhubarb odor. Microscopically its structure is similar to the imported but it is distinguished by the small amount of Calcium oxalate crystals present. The powder is of a fair color. E. H. GANE. 
Saffron-Valencia. Five years ago it was almost impossible to encounter an importation of this drug which was genuine and of proper quality. Numerous substances other than Saffron were doctored up so as to resemble it. Petals and stamens of saffron flowers were included with the stigmas, frequently to the extent of $25 \%$ or more. Genuine saffron was coated and weighted with heavy adulterants, or was soaked in oil to increase its weight. An excessive amount of moisture was frequently present. In view of the very great value of this article commercially, the money loss entailed in these ways in the course of the year reached an enormous figure. It is safe to say that at the present time it is as rare an occurrence to see an importation of saffron that is defective in any way as it used to be to see a perfect one. I think the money saving in this one.article alone will more than pay the entire costs of the enforcement of the Pure Food and Drug Law at the Port of New York. H. H. RusBy.

Salvia. It is apparent that much of the "Sage" that is imported, especially around Thanksgiving time, consists of the Salvia Triloba and other very similar species. These all have an odor and flavor closely resembling those of the official article though differing considerably in strength. It may be that they are mere varieties of Salvia officinalis and might properly be officially included with it. Nevertheless, the question should be thoroughly studied and the proper status of these substitutes be definitely fixed. H. H. Rusby.

SCAM MONy. One sample offered only contained $28.6 \%$ resin and was largely adulterated with wheat flour. E. H. GANE. It has been boldly claimed, by those who ought to know better, that practically all the scammony on the market is extracted from the dried root of the false or Mexican scammony. While it is true that most of the scammony on the market, perhaps one should say practically all of it, violates the U. S. P. requirements in having been extracted from the dried instead of the living root of Scammony, the amount of that coming from Mexican scammony, although large, does not predominate. H. H. Rushy.

SEN. The sale of broken senna as "Senna U. S. P." has been very properly authorized by the government, but that of senna siftings, containing large amounts of sand and other foreign matter, has caused great trouble. Here again the efforts of the Federal Government are doubtless neutralized in most cases by the neglect of the states to carry out the taboo. H. H. RusBy.

Silver Nitrate A mpuls. Material-celluloid. Claim 1\% solution-permanent-convenient. Used for dropping in eyes of new-born babies. 12-10-1910-Assayed $11 / 4 \%$. No trace of oxidation. Walls of ampuls average 1-200 inch in thickness. Solution may have grown stronger by evaporation.

$$
\begin{gathered}
\text { Five ampuls weighed } 2.457 \mathrm{Gm} \text {. } \\
\text { Loss in one month } \\
\text { L-11-1911 Five }
\end{gathered}
$$

About $.075 \mathrm{G}$. for each ampul. No oxidation. Strength of solution $1.85 \%$.

2-17-1911 5 ampuls weighed $1.595 \mathrm{G}$. Loss since 1-11-1911 .485 G

About $.097 \mathrm{G}$. for each ampul. Some show marked reduction. Solution from all five ampuls, mixed, assayed $2.76 \%$. As a two percent solution is dangerous this solution of $2.76 \%$ should not be used. E. L. Patch.

SoAP. Soap Castile. The powdered contains 2.5 to $5 \%$ of water. The cake 11 to $26 \%$. Much offered as castile soap is made from animal fats. W. L. Scoville. Much of the so-called "Pure Olive Oil Soap" contains a large proportion of cocoanut oil soap. This is easily recognized by the characteristic taste. E. H. GANE.

Soda-Caustic. Runs from $88 \%$ to $98.6 \%$. W. L. Scoville.

Sodium Carbonate. Varies greatly in the amount of water which it contains. W. L. SCOVILLE.

SOdiUM Glycerophosphate. Is often alkaline in reaction to a very marked extent. Enough to give trouble in preparations containing it. W. L. Scoville.

Sodium Phosphate. Dried, Purified No. 1. Contained $10 \%$ sulphate, $1.5 \%$ water. U. S. P. No. 2. Contained excess of sulphate and chloride. 0.5 water. E. L. PATch.

Sodium Sulphate. Dried. Tests satisfactory-nearly anhydrous. E. L. PATCH.

Sodium Sulphite. Dried.

No. 1100 parts $=188$ crystalline-tests $O . K$. No. 2100 parts $=189$ crystalline-tests $\mathrm{O}$. K. No. 3 Tests $99 \% 0.26$ chloride-No. 4-98\%0.38 chloride.

No. 5 Too dirty to use. E. L. Patch.

Stramonium. Two lots of domestic assayed 0.17 and $0.14 \%$ alkaloids. E. H. GANE. $0.198 \%, 0.21 \%, 0.41 \%, 0.28 \%$. E. L. PATCH.

Tragacanth: Has been a bone of fierce contention during the year; two fraudulent practices, which must be separately discussed, having been commonly indulged in, namely, the sale of India gum in place of or mixed with Tragacanth, and the sale of a grade of Tragacanth which does not meet the official standard. India gum is any gum, of either an Acacia or Tragacanth type, collected in India. The varieties are numerous and of very variable character. All of the Tragacanth type are more or less dark colored with adhering fragments of bark. All are deficient in adhesiveness and other properties of Tragacanth, one having no adhesive power whatever. They are very cheap and their substitution has been a very highly profitable form of fraud. All possess important uses in the arts, and their exclusion, when truly named, is entirely unjustifiable. All too, may lose their true names and go into use as Tragacanth, the states paying not the slightest attention to the fraud. The description of the pharmacopoia is ample to distinguish the article in the entire state, but useless when it is powdered. Since the law says that articles must conform to the standards of the pharmacopeia as determined by the tests laid down therein, an opportunity exists for sub- 
stitution, even though tests not included in the pharmacopoeia may be conclusive, as in fact they are. In the Federal District of New York the procedure of the courts has mostly been such as to result in the high encouragement of the violators of the Food and Drugs Act. Although there have been some commendable exceptions, there has also been much seen of the evil of false testimony of experts. In one case the importer admitted to the Federal authorities that his Tragacanth contained a large admixture of India gum, but afterwards decided to contest the case. He had not the slightest difficulty in finding experts willing to swear that they had applied the tests and found the article pure. The tests then being applied in court, one of the witnesses who was present refrained from looking on, explaining after the trial that he might be compelled to testify to what he saw if he looked at the tests, which would invalidate his previous testimony. There is a manifest serious weakness in the law that makes no provision for the evidence of tests discovered in the intervals between the publications of the pharmacopœia. Moreover, now that the oharmacopoia is the legal standard, it must be far more careful of both the accuracy and sufficiency of its tests than it has heretofore been. Concerning the supply of a lower grade of genuine Tragacanth than the pharmacopceia specifies I am compelled to express my sympathy with the offenders, except as to the technical matter of violating the law. The restriction of the $U$. $S$. $P$. to a number one Tragacanth (and the same is true of Acacia) would seem to be purely fanciful and uneconomical. A second, third and even fourth grade of these gums, when powdered, can scarcely be distinguished from a number one, certainly not unless a number one sample is placed beside it for comparison. The writer is not convinced that any medicinal or pharmaceutical use for a number one Acacia or Tragacanth cannot be satisfactorily met by one of the other grades mentioned. This opinion, being firmly held by dealers and users makes it extremely difficult to prevent them from substituting such grades and this is certain to $\mathrm{ba}$ done after powdering, since detection is then impossible. H. H. RusBY.

TRITICUM. A single shipment of a grass rhizome somewhat resembling Triticum, but totally distinct therefrom, has been offered and rejected under this name. $H$. $H$. RusBy.

Turpentine. Adulterated with copal. Several severe inflammations of the hands and face have resulted. To identify the copal the liquid is distilled up to $190^{\circ} \mathrm{C}$. and the acid and bromine members of the residue determined. Pharm. ERA.

Umbeifferous Cremocarps. Caraway, Anise, Fennel, etc., etc. This class of official fruits is extremely liable to contamination with large amounts of stems, gravel, sand, dust, weed seeds and other impurities, but the indications of quality thus resulting are very deceptive. Sometimes the appearance of foreign tissue will be such as to give the impression of an article of very low grade, yet separation of the light chaff and stem fragments will show the percentage of the latter to be insignificant, while at other times a very fair looking article will be found to contain a serious admixture of heavy and perhaps inert impurities. H. H. RusBy.

UvA URSI. The production of cut stems to this drug in the same way as described in connection with Long Buchu, seems to have nearly ceased, a result apparently of the persistent rejection of the article when so treated. H. H. RusBY.

ZINC OXIDE. Difficult to obtain strictly U. S. P. The usual impurities are lead, antimony and iron in excess. Seven lots offered as U. S. P. assayed $96.4 \%, 98.14 \%, 99.09 \%$, $96.1 \%, 95.8 \%, 97.2 \%$ and $95.3 \%$ Zinc. E. H. GANE.

For the Committee:

Edgar L. Patch.

E. H. Gane.

H. H. ResBY.

W. L. SCOVILle.

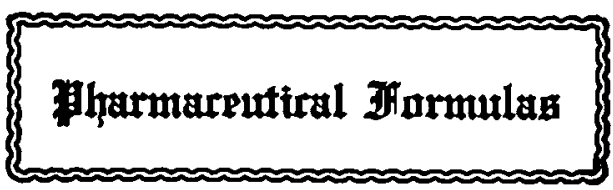

\section{PROPOSED FOR A. PH. A. RECIPE BOOK.}

(Continued from page 368 )

The first two formulas belong to the lubricating jellies submitted in the April Jours al A. Pн. A.

The other formulas are for preparations of "scarlet red" in the form of ointments and dusting powders. As these preparations are frequently ordered by physicians the. writer deemed it advisable to include various formulas given by authorities for the enlightenment of the pharmacists and their physician friends.

The members are requested to submit formulas and also send comments on those already published.

Respectfully submitted,

Otto Raubenheimer, Chairman.

$$
<>
$$

\section{ABBREVIATIONS}

used in Department of Pharmaceutical Formulas, and in Department of Synonyms.

Am. Dis.-American Dispensatory.

Anvers-Formulaire de la Société de Pharmacie d'Anvers.

Aust.Pharmacopœea Austriaca.

Belg.-Pharmacopcea Belgica.

B P.-British Pharmacopceia. 